\title{
Assessment of the impact of digitalization on the formation of strategic corporate interests of the company using the apparatus of fuzzy logic
}

\author{
Viktoriia Kokhanova* \\ Private educational institution of higher education «SOUTHERN UNIVERSITY (IMBL)», \\ M.Nagibina av., 33A/47, 344068Rostov-on-Don, Russia
}

\begin{abstract}
Faced with the need to implement digital tools / processes, the company is forced to independently calculate not only costs, but also methods and mechanisms for assessing the effectiveness of these innovations. In this situation, it is necessary to choose, among other things, methods and assessment tools, and the use of the apparatus of fuzzy logic can be used as one of the tools. In this article, we give an example of using the apparatus of fuzzy logic, indicate the criteria that can be used as criteria for building a system for assessing the effectiveness of digitalization in order to achieve the strategic corporate interests of the company, and also provide an overview of the available developments. Within the framework of the article, we have also identified the directions of modification of classical assessment methods that are possible using the apparatus of fuzzy logic.
\end{abstract}

\section{Introduction}

The development of the digital economy does not give companies the opportunity to stay on the sidelines; companies increasingly have to think about the choice of technology or methodology for introducing digital technologies into their activities. In this situation, the assessment of the economic feasibility of these technologies comes to the fore.

In our opinion, it is necessary to provide for the following main directions digital transformation: creation and development of new business models; formation of a new approach to data management; digital modelingimplementation of information technologies and online systems; creation of a digital ecosystem of the company.

As part of the subject matter of this article, we will dwell in more detail on the issue of creating a digital ecosystem and assessing its effectiveness from the standpoint of the company's strategic corporate goals.

\footnotetext{
${ }^{*}$ Corresponding author: kohanovavs@yandex.ru
} 


\section{Methods for assessing the economic efficiency of digitalization using fuzzy logic tools}

To assess the feasibility, you can use a variety of tools, including tools of fuzzy logic.

The following ideas of fuzzy logic are most in demand. According to the basic idea of fuzzy logic, all levels of economic parameters can be measured not only quantitatively, but also qualitatively, which is important for us within the framework of the task at hand. To do this, it is necessary to define the linguistic variable "Level of parameter X", the carrier of which is the domain of definition of the parameter $\mathrm{X}$, in this situation $\mathrm{X}$ can take on values of the subset "very low level, low level, medium level, high level, very high level".

For pentascals, it is necessary to construct a system of membership functions of the carrier $\mathrm{X}$ to the corresponding fuzzy subsets. The simplest way to set is a system of trapezoidal fuzzy numbers [1]. This idea corresponds to the use of a system of fuzzy-logical conclusions - standard fuzzy multi-level $[0,1]$ - classifiers.

The pentascal is optimal in most cases [2], but if necessary, you can use the simplest case of a binary scale such as High, Low or Bad, Good. Depending on the statement of the problem, the number of terms can vary: for example, in accordance with the established classification of assessing the state of systems, three, four or even ten terms can be used [36]. If the number of terms is not definitively determined, it is possible to use not trapezoidal, but sigmoid membership functions possessing smoothness sufficient for mathematical rigor and defined by the formulas:

$$
\mu_{k}=\exp \left(-\left(x-\frac{k-1}{4}\right)^{2 n} / \sigma^{2 n}\right), k=1,2,3,4,5 .
$$

Here $n \in N$ is a natural number characterizing the steepness of the graph of the membership function. The nodes of the classifier, respectively, are located at the points:

$$
\overline{g_{k}}=\frac{k-1}{4}, k=1,2,3,4,5 \text {. }
$$

The parameter $\sigma$ is selected based on the completeness of the constructed system of functions. Indeed, we require that at the intersection points of two adjacent graphs the following relationship holds:

$$
\mu_{k}\left(\frac{k-1}{4}+\frac{1}{8}\right)=\mu_{k+1}\left(\frac{k-1}{4}+\frac{1}{8}\right)=\frac{1}{2} .
$$

Final form of membership functions has the form:

$$
\mu_{k}=\exp \left(-\left(x-\frac{k-1}{4}\right)^{2 n} 8^{2 n} \ln 2\right), k=1,2,3,4,5 .
$$

The given system (3) is characterized by completeness, therefore, it can be used to develop a five-level classifier. Thus, the above formulas can be connected as follows:

$$
\mu_{k}=\exp \left(-\left(x-\frac{k-1}{4}\right)^{2 n} 2^{2 n}(K-1)^{2 n} \ln 2\right), \quad \overline{g_{k}}=\frac{k-1}{K-1}, k=1,2, \ldots, K
$$




\section{Tools for analyzing the main data sources to assess the effectiveness of digitalization in terms of the strategic corporate interests of the company}

Anticipating the assessment of the effectiveness of digitalization of the company, it is necessary to outline the basis for analysis. We need to select in the sample companies that can be designated as financially stable, actively introducing digital technologies, and on the other hand, the average, so to speak, enterprises whose experience can be broadcasted to all similar enterprises. That is, the question of the representativeness of the sample is quite acute.

To assess the impact of digitalization on the formation of strategic corporate interests of the company, we used data on companies from the rating of 600 largest companies in Russia RAEX-600, the Sustainable Development Vector index of the RUIE.

To assess, we need to determine not only the sources of information, but also the criteria for the assessment. We suggest using the following KPIs as criteria:

1. Financial strategy:

1.1. Increase in assets,

1.2. Capital gains,

1.3. Loan growth, (share of borrowed capital)

1.4. Asset turnover,

1.5. Increase in profitability,

1.6. Financial stability assessment

1.7. Dynamics of investment in innovation

2. Production strategy:

2.1 Dynamics of sales

2.2 Dynamics of production volume

2.3 Labor productivity dynamics

2.4 Marriage rate

3. Branding strategy:

3.1 Goodwill

3.2 Increase in the market value of the company

3.3 Availability of an innovative development program

4. Organizational strategy:

4.1 Dynamics of staff turnover

4.2 Personnel engagement rate

4.3 Innovation Index,

4.4 Personnel Creativity Index

4.5 Employment satisfaction index

5. Marketin gstrategy:

5.1 Marketing expenses.

Note that the growth of not only the information flows themselves, but also the quantity and quality of methods for analyzing this information act as the main driving forces for the modification of management and forecasting models in corporations.

Digital technologies act as a trigger for constant changes in the formats of functioning within the business, contribute to the formation of new opportunities, due to which new forms of management objects, new forms of business, etc. appear. In parallel with this, digital technologies pose challenges to the existing management system.

In order to be able to assess the effectiveness of the digital ecosystem, in our opinion, it is necessary to introduce the following variables:

$\mathrm{d}$ - coefficient of influence of digitalization on the formation of strategic corporate interests of the company 
$\mathrm{t}$ - time moment

$\mathrm{F}$ is some operator that integrates the action of the entire set of factors in the i-th area of interest, while considering $\mathrm{n}$ areas

$\mathrm{W}_{1}$ - a set of some external disturbances

$\mathrm{W}_{2}$ - a set of some internal disturbances

e - random factor

$$
d(t)=\sum_{i=1}^{n} F_{i}\left(t, W_{1}, W_{2}, e\right)
$$

A set of some external disturbances $\left(\mathrm{W}_{1}\right)$ may include indicators: the level of investment in the company as a whole, the share of investment in innovation, the increase in the company's market value.

A set of some external disturbances $\left(\mathrm{W}_{2}\right)$ may include indicators: dynamics of sales, dynamics of production volume, labor productivity dynamics, marriage rate, capital gains, loan growth, (share of borrowed capital), asset turnover, increase in profitability, financial stability assessment, dynamics of investment in innovation, the presence of an innovative development program and others.

Analysis of the literature shows that the possibility of these modifications has already been considered by experts in a number of studies of the stability of economic systems.

YachmenevaV.M. [5] offers an assessment of the level of economic sustainability of an enterprise based on fuzzy logic. To assess the ability of an enterprise to reflect external threats, maintain and ensure its financial stability, carry out its current activities fully, Yachmeneva suggests introducing a fuzzy number $\mathrm{X}$ from the range. The higher the $\mathrm{X}$ value, the more stable the enterprise.

Karpova N.A. [6] developed a methodology for assessing the sustainability of consolidated groups of companies based on a combination of fuzzy-multiple and cognitive approaches to modeling. Algorithms developed by O.A. Nedosekin to assess the risk of company bankruptcy [7]. In another article, Karpova N.A. it is noted that the adoption of managerial decisions is aimed at maintaining or changing the existing situation [8], which means that the control system built on the principles of fuzzy logic will be dynamic, supporting all changes in the enterprise, taking into account their predicted values. This conclusion is confirmed by E.Yu. Khrustalev, O.E. Khrustalev [9], the work shows that to understand the functioning of complex systems, the most effective is the use of fuzzy cognitive models, since they also allow predicting the course of development of the system.

Currently, fuzzy logic is spreading its influence as a tool for analysis, is used in the development of various methods of data mining, widely used in the study of economic processes. An example of this is:

- fuzzy neural networks;

- $\quad$ adaptive fuzzy systems;

- $\quad$ fuzzy queries to databases (fuzzy queries);

- fuzzy associative rules;

- fuzzy cognitive maps.

Compared to "pure" methods of data mining, fuzzy-multiple modifications have wider opportunities to take into account the uncertainty of external conditions and expert assessments, greater compactness, clarity and ease of use.

\section{Conclusions}

The choice of a parameter and its justification is a separate, rather developed area of research. The corresponding methods for constructing quantitative assessments of the stability of economic systems, with their undoubted practical value and relevance, have a 
number of disadvantages. This is typical of classical economic models and is irresistible within the framework of the traditionally used mathematical apparatus. At the same time, they can be overcome with the help of a fuzzy logic apparatus, including fuzzy logic inference systems. Currently, active work is underway to modify traditional mathematical methods based on fuzzy logic, which will make it possible in the foreseeable future to achieve significant success in creating a modern mathematical apparatus that meets the challenges of the digital economy.

\section{References}

1. L. K. Konysheva, D. M. Nazarov, Fundamentals of the theory of fuzzy sets: a training manual, 192 (2011)

2. N. G. Vovchenko, M.B. Stryukov, L.V. Sakharova, O.V. Domokur, Advances in Intelligent Systems and Computing, 896, 709 (2019)

3. E. A. Arapova, G. V. Lukyanova, L. V. Sakharova, G. I. Akperov, Advances in Intelligent Systems and Computing, 896, 643

4. L.V. Sakharova, T.V. Alekseychik, T.V. Bogachev, E.A. Arapova, Bulletin of the Rostov State University of Economics, 3(63) (2018)

5. V.M. Yachmeneva, Economics and Management, 4-5, 107 (2007)

6. N.A. Karpova, Bulletin of Eurasian science, 5(30)(2015)

7. A.O. Nedosekin, Mathematical foundations of modeling financial activities using fuzzy-plural descriptions: dis doct. econ. Sciences, 280 (2003)

8. N.A. Karpova, Economy, Business, Banks, 2(3), 118 (2013)

9. E.Yu. Khrustalev, O.E. Khrustalev, Economic analysis: theory and practice, 10(313), 2 (2013) 